\title{
Expanding the Phenotype of Homozygous KCNMA1 Mutations; Dyskinesia, Epilepsy, Intellectual Disability, Cerebellar and Corticospinal Tract Atrophy
}

\author{
Gözde Yeşi11, Ayşe Aralaşmak², Enes Akyüz1, Dilara İçağasığlu33, Türkan Uygur Şahin4, Yavuz Bayram5 \\ ${ }^{1}$ Department of Medical Genetics, Bezmialem Vakıf University School of Medicine, İstanbul, Turkey \\ ${ }^{2}$ Department of Radiology, Bezmialem Vakıf University School of Medicine, İstanbul, Turkey \\ ${ }^{3}$ Department of Child Disease and Health, Bezmialem Vakıf University School of Medicine, İstanbul, Turkey \\ ${ }^{4}$ Department of Child Neurology, Bezmialem Vakıf University School of Medicine, İstanbul, Turkey \\ ${ }^{5}$ Mol. \& Human Gene/Lupski Lab, Baylor College of Medicine, Texas, USA
}

\begin{abstract}
Background: The $K C N M A 1$ gene encodes the $\alpha$-subunit of the large conductance, voltage, and calcium-sensitive potassium channel (BK channels) that plays a critical role in neuronal excitability. Heterozygous mutations in KCNMAl were first illustrated in a large family with generalized epilepsy and paroxysmal nonkinesigenic dyskinesia. Recent research has established homozygous KCNMA1 mutations accountable for the phenotype of cerebellar atrophy, developmental delay, and seizures.

Case Report: Here, we report the case of a patient with a novel homozygous truncating mutation in KCNMA1 (p.Arg458Ter)
\end{abstract}

presenting with both the loss- and gain-of-function phenotype with paroxysmal dyskinesia, epilepsy, intellectual delay, and corticospinalcerebellar tract atrophy.

Conclusion: This report extends the KNCMA1 mutation phenotype with a patient who carries a novel frameshift variant, presenting with both the gain- and loss-of-function phenotypes along with spinal tract involvement as a novel characteristic.

Keywords: Cerebellar atrophy, dyskinesia, epilepsy, KCNMA1, spinal tract atrophy
The KCNMA1 gene encodes the $\alpha$-subunit of the large conductance, voltage, and calcium-sensitive potassium channel (BK channels), which is also activated by the concentration of cytosolic $\mathrm{Mg}^{2+}$ and is known to be predominantly expressed in the amygdala, caudate nucleus, cerebral cortex, hippocampus, hypothalamus, spinal cord, and Purkinje cells in the cerebellum $(1,2)$. Initially, the KCNMA1 mutations were illustrated in a large family with generalized epilepsy and paroxysmal nonkinesigenic dyskinesia (3). A recent study established a correlation of the homozygous KCNMA1 mutation with cerebellar ataxia, developmental delay, and seizures. In addition, both the gain- and loss-of-function have been proposed as the underlying molecular mechanism in this channelopathy resulting in increased excitability (4). Here, we report the case of a patient with a novel homozygous truncating mutation in KCNMA1 (p.Arg458Ter) presenting with both the loss- and gain-of-function phenotype with paroxysmal dyskinesia, epilepsy, intellectual delay, and corticospinal-cerebellar tract atrophy.

\section{CASE PRESENTATION}

A 15-year and 11-month-old male patient was referred to our genetics unit at the age of 15 years. He was born at term to a thirddegree consanguineous healthy parents with a healthy birth weight (3250 g), height $(53 \mathrm{~cm})$, and occipitofrontal circumference (34 $\mathrm{cm})$. There was a prolonged labour, and the APGAR score was 7-8. His motor milestones were delayed, and he never walked alone. In addition, he had a social smile and could talk approximately 10 simple words. His seizures, although mostly absent, started at the age of 18 months and were well-controlled by valproic acid. Meanwhile, he also experienced clonic and generalized tonicclonic (GTCS) and atonic seizures and had spasticity predominant in the lower extremities with no pathological reflexes. While electroencephalography revealed generalized spike-wave activities, electromyography and metabolic tests were normal. Furthermore, the brain magnetic resonance imaging (MRI) performed at the age of 3 years revealed moderate atrophy with prominent folia in the upper parts of the supratentorial cerebellar vermian region.

\footnotetext{
Address for Correspondence: Dr. Gözde Yeşil, Department of Medical Genetics, Bezmialem Vakıf University School of Medicine, İstanbul, Turkey Phone: +90 $5066487808 \quad$ e-mail: drgyesil@gmail.com ORCID ID: orcid.org/0000-0003-1964-6306 
Moreover, symmetric T2 hyperintensities were observed at the retroatrial periventricular deep white matter. Diffusion tensor imaging images obtained at the age 14 years revealed the involvement of tegmental to corticospinal atrophy (Figure 1). Besides, the atrophy of the cerebellum had progressed compared to previous MRI studies (Figure 2). The patient's last examination determined contractures on the large joints, dyskinetic tremor, and dystonia. Of note, this study was reported per the tenets of the Declaration of Helsinki and was approved by the institutional review board and ethical committee of our university. We obtained written informed consent from the patient.

The exome sequencing revealed a homozygous nonsense change in the KCNMA1 gene NM_001161352.1:c.1372[C>T]; [C>T] NP_001154824.1:p.[(Arg458*)];[(Arg458*)]. The variant was not observed in any publicly available database (e.g., EXAC, EVS, and 1000 genomes) or in our internal database. In addition, we identified another variant, rs60734921, in the CACNAH1 gene, which has been described in a study as a risk factor for generalized


FIG. 1. a, b. Sagittal and coronal brain magnetic resonance images of a 14-year-old boy revealed cerebellar vermian volume loss with normal pons and spinal canal (a). Diffusion tensor imaging images displayed thinning of the tegmental extending through corticospinal tracts (b).
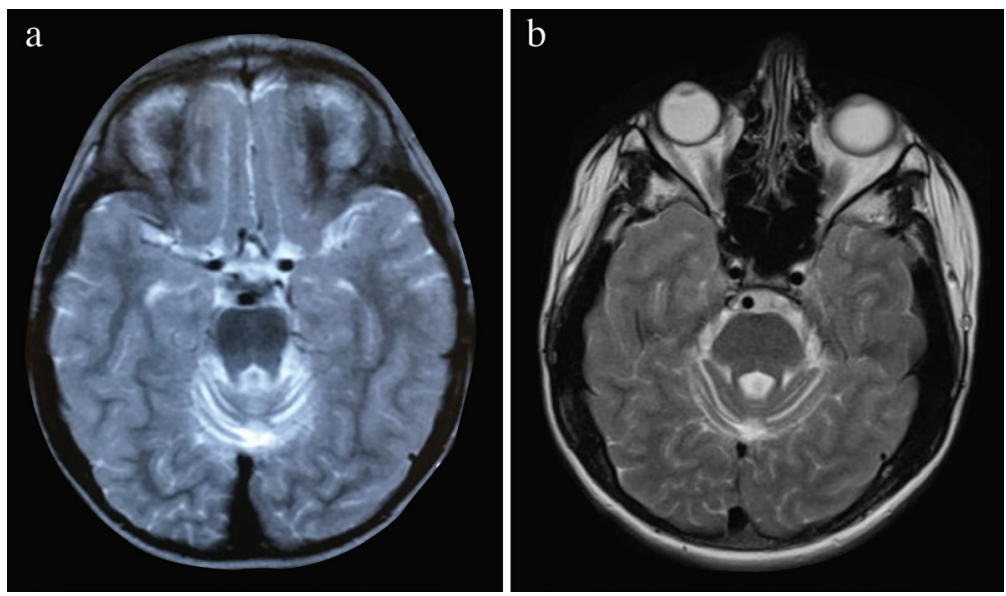

FIG. 2. a, b. Compared to previous magnetic resonance imaging, the atrophy of the cerebellum progressed; (a) performed when he was of 3 years and (b) performed 12 years after the initial magnetic resonance imaging. 
TABLE 1. The clinical and characteristic phenotype of patients with the KCNMA1 gene mutation

\begin{tabular}{|c|c|c|c|c|c|c|}
\hline Clinical features & Current study & $\begin{array}{l}\text { Tabarki et al. (4) } \\
\text { (2016) }\end{array}$ & $\begin{array}{l}\text { Tabarki et al. (4) } \\
\text { (2016) }\end{array}$ & $\begin{array}{c}\text { Khosravani et al. (5) } \\
\text { (2015) }\end{array}$ & $\begin{array}{c}\text { Khosravani et al. (5) } \\
\text { (2015) }\end{array}$ & Du et al. (3) (2005) \\
\hline Sex & Male & Female & Female & Male & Male & 10 males, 6 females \\
\hline Age of onset & 1.5 years & 8 months & 8 months & 20 days & 7 months & 6 months to 15 years \\
\hline Perinatal history & Unremarkable & Unremarkable & Unremarkable & Unremarkable & Unremarkable & Unremarkable \\
\hline Family history & Negative & Positive & Positive & Negative & Negative & Positive \\
\hline Inheritance & Autosomal recessive & Autosomal recessive & Autosomal recessive & Not specified & Not specified & Autosomal dominant \\
\hline Seizures & $\begin{array}{c}\text { Absence, Atonic to } \\
\text { GTCS }\end{array}$ & $\begin{array}{l}\text { Myoclonic seizures } \\
\text { evolving to tonic and } \\
\text { GTCS }\end{array}$ & Myoclonic seizures & $\begin{array}{c}\text { Yes } \\
\text { (not specified) }\end{array}$ & $\begin{array}{c}\text { Yes } \\
\text { (not specified) }\end{array}$ & Absence, GTCS \\
\hline EEG & $\begin{array}{c}\text { Focal and } \\
\text { generalized spike } \\
\text { waves }\end{array}$ & $\begin{array}{l}\text { Lennox-Gastaut } \\
\text { pattern }\end{array}$ & $\begin{array}{l}\text { Mild background } \\
\text { slowing }\end{array}$ & Normal & Normal & $\begin{array}{l}\text { Generalized spike- } \\
\text { wave complexes }\end{array}$ \\
\hline $\begin{array}{l}\text { Paroxysmal } \\
\text { nonkinesigenic } \\
\text { dyskinesia }\end{array}$ & + & - & - & + & + & + \\
\hline MRI & $\begin{array}{l}\text { Cerebellar and spinal } \\
\text { tract atrophy }\end{array}$ & Cerebellar atrophy & Cerebellar atrophy & Normal & Normal & Normal \\
\hline $\begin{array}{l}\text { KCNMA1 } \\
\text { mutation }\end{array}$ & $\begin{array}{c}\text { c. } 1372 \mathrm{C}>\mathrm{T} \\
\text { (homozygous) }\end{array}$ & $\begin{array}{c}\text { c.2026dupT } \\
\text { (homozygous) }\end{array}$ & $\begin{array}{c}\text { c.2026dupT } \\
\text { (homozygous) }\end{array}$ & $\begin{array}{c}\mathrm{c} .2650 \mathrm{G}>\mathrm{A} \\
\text { (heterozygous) }\end{array}$ & $\begin{array}{c}\mathrm{c} .3158 \mathrm{~A}>\mathrm{G} \\
\text { (heterozygous) }\end{array}$ & $\begin{array}{c}\mathrm{c} .1301 \mathrm{~A}>\mathrm{G} \\
\text { (heterozygous) }\end{array}$ \\
\hline Protein & p.Arg458Ter & p.(Try676Leufs*7) & p.(Try676Leufs*7) & p.Glu884Lys & p.Asn1053Ser & p.Asp434Gly \\
\hline Inheritance & Autosomal recessive & Autosomal recessive & Autosomal recessive & de novo & de novo & Autosomal dominant \\
\hline
\end{tabular}

idiopathic epilepsy (5). While the population frequency of the variant in the CACNAH1 gene was $0.0012 / 39$ according to the EXAC, it was classified as a variant of unknown significance in the dbSNP database (Table 2).

\section{DISCUSSION}

Large-conductance calcium-sensitive BK channels are one of the potassium channels that hyperpolarize the neurons and are encoded by KCNMA1 $(6,7)$. Reportedly, mutations in KCNMA1 have been identified in clinical cases of epilepsy and paroxysmal nonkinesic dyskinesia $(3,8)$. In addition, a study functionally investigated the $D 434 G$ mutation of KCNMA1 by the patch clamp method and was found to be associated with the gain of function (3). Some studies have suggested that the gain of function at BK channels resulted in the faster and rapid repolarization of the action potential in the syndrome mechanism, accounting for an increase in the excitability of the brain $(3,9)$. Moreover, Sausbier et al. $(2,10)$ reported that KCNMA1/-/ mice exhibited abnormal eye-blink reflex, abnormal locomotion, and abnormal motor coordination. Thus, either gainor loss-of-function mutations might result in the disease phenotype. Furthermore, both the gain- and loss-of-function phenotype can be observed in other channelopathies such as KCNA2, GRIN1, and $D E A F 1$ gene mutations.

Recently, Tabarki et al. (4) reported a different phenotype of the same gene. In their study, the siblings were homozygous for a frameshift variant in KCNMA1 and had tractable myoclonic seizures starting around the age 1, which later evolved into tonic and GTCS type. In addition, they had a severe developmental delay, but no dyskinesia, and their brain MRI revealed cerebellar
TABLE 2. Annotations, frequency, and bioinformatic prediction scores of variants in select candidate genes

\begin{tabular}{lcc}
\hline Gene & KCNMA1 & CACNA1H \\
\hline Position [hg19] & $10: 78846314$ & $16: 1252303$ \\
Nukleotit change & c.1372C $>$ T & c.1853C $>\mathrm{T}$ \\
Protein change & p.Arg458Ter & p.Pro618Leu \\
Zygosity & Hom & Het \\
EXAC frequency & - & 0.001201 \\
PhyloP score & 2.672 & 4.985 \\
PhyloP prediction & Conserved & Conserved \\
SIFT score & - & $(0.01)$ \\
SIFT prediction & - & Deleterious \\
Polyphen2 score & - & $(0.991)$ \\
PolyPhen prediction & - & Probably_damaging \\
Mutation taster score & 1 & 0.999 \\
Mutation taster & Disease causing & Disease causing \\
prediction & & \\
dbSNP ID & - & rs60734921 \\
Read depth & 170 & 47 \\
Transkript & NM_001161353 & NM_021098.2 \\
Exon & $11 / 28$ & $9 / 35$ \\
\hline
\end{tabular}

atrophy that was not a feature of previously reported heterozygous mutations (4). Table 1 summarizes the clinical and characteristic features of patients with KCNMA1 mutations. Unlike previous reports, our case had corticospinal and tegmental tract involvement 
besides cerebellar atrophy, which could be attributed to the possible progressive course of the disease attributive to the advanced age of our patient. In addition, our patient had dyskinesia and dystonic movements, which were not known for biallelic mutations. Reportedly, the variant found in the CACNA1H gene could also contribute the proband's phenotype; however, the variant is a known single nucleotide polymorphism that was considered a risk factor for generalized epilepsy but not the dyskinesia phenotype (5). In conclusion, this report presents a unique case of a patient who manifested both phenotypes of the gain- and loss-of-function mutations of KCNMA1 (dyskinesia, epilepsy, and cerebellar atrophy) and had tegmental and spinal tract atrophy that has not been reported to date. Thus, electrophysiological analyses and expression studies are warranted to gain an insight into functional consequences of biallelic mutations of the KCNMA1 gene. Overall, this study highlights the importance of using exome sequencing techniques for expanding the disease phenotypes to reveal the disease pathogenesis.

Conflict of Interest: No conflict of interest was declared by the authors.

\section{REFERENCES}

1. Lee US, Cui J. BK channel activation: structural and functional insights. Trends Neurosci 2010;33:415-23.
2. Sausbier M, Hu H, Arntz C, Feil S, Kamm S, Adelsberger H, et al. Cerebellar ataxia and Purkinje cell dysfunction caused by $\mathrm{Ca} 2+$-activated $\mathrm{K}+$ channel deficiency. Proc Natl Acad Sci U S A 2004;101:9474-8.

3. Du W, Bautista JF, Yang H, Diez-Sampedro A, You SA, Wang L, et al. Calciumsensitive potassium channelopathy in human epilepsy and paroxysmal movement disorder. Nat Genet 2005;37:733-8

4. Tabarki B, AlMajhad N, AlHashem A, Shaheen R, Alkuraya FS. Homozygous KCNMA1 mutation as a cause of cerebellar atrophy, developmental delay and seizures. Hum Genet 2016;135:1295-8.

5. Khosravani H, Bladen C, Parker DB, Snutch TP, McRory JE, Zamponi GW. Effects of Cav3.2 channel mutations linked to idiopathic generalized epilepsy. Ann Neurol 2005;57:745-9.

6. Shao LR, Halvorsrud R, Borg-Graham L, Storm JF. The role of BK-type Ca2+ -dependent $\mathrm{K}+$ channels in spike broadening during repetitive firing in rat hippocampal pyramidal cells. J Physiol 1999;521:135-46.

7. Gu N, Vervaeke K, Storm JF. BK potassium channels facilitate high-frequency firing and cause early spike frequency adaptation in rat CA1 hippocampal pyramidal cells. J Physiol 2007;580:859-82.

8. Zhang ZB, Tian MQ, Gao K, Jiang YW, Wu Y. De novo KCNMA1 mutations in children with early-onset paroxysmal dyskinesia and developmental delay. Mov Disord 2015;30:1290-2.

9. Diez-Sampedro A, Silverman WR, Bautista JF, Richerson GB. Mechanism of increased open probability by a mutation of the BK channel. J Neurophysiol 2006;96:1507-16.

10. Sausbier U, Sausbier M, Sailer CA, Arntz C, Knaus HG, Neuhuber W, et al. Ca2+ -activated $\mathrm{K}+$ channels of the BK-type in the mouse brain. Histochem Cell Biol 2006;125:725-41. 